\title{
Effect of lidocaine on the safety of postoperative skin reconstruction after malignant melanoma resection
}

\author{
KAIMEI XU ${ }^{1}$, JINGJING WANG ${ }^{2}$, LIU YANG ${ }^{2}$, LIANGBIN WAN $^{1}$ and YANBING WANG ${ }^{2}$ \\ Departments of ${ }^{1}$ Pathology and ${ }^{2}$ Anesthesiology, Bishan Hospital, \\ Bishan, Chongqing 402760, P.R. China
}

Received August 24, 2018; Accepted November 21, 2018

DOI: $10.3892 / \mathrm{etm} .2019 .7519$

\begin{abstract}
Malignant melanoma is a type of skin cancer with high morbidity and mortality. Therapeutic strategies should be individualized in order to increase the survival rate. The aim of this study was to assess the effect of lidocaine on skin healing and immune function after operation of patients with melanoma. Sixty patients with melanoma were selected from those treated in Bishan Hospital between August 2014 and August 2016. The patients were randomly divided into lidocaine group and control group. Lidocaine group was locally treated with an intradermic injection of $2 \%$ lidocaine solution in dose of $1.5 \mathrm{mg} / \mathrm{kg}$ and the control group received the same quantity of saline solution. In the lidocaine group, the rates of skin temperature, drug reaction, healing and infection were higher than the corresponding rates in the $\mathrm{C}$ group. The local application of lidocaine can promote wound healing to a certain extent, reduce pain, and promote postoperative skin reconstruction.
\end{abstract}

\section{Introduction}

Malignant melanoma has always been an alarming health problem, with high morbidity and mortality (1). The etiology of melanoma is not completely identified, comprising different risk factors, such as ultraviolet radiation exposure, genetics, chemical exposure and HPV infection (2-4). The therapeutic strategies are individualized according to the stage of the disease and the prognosis. The 5-year survival rate, also depends on the stage and the prognosis (5). If the malignant cells have reached the lymph nodes, surgical resection is the main treatment of solid tumors. However, in the perioperative period due to various factors, such as surgery and anesthesia, tumor cells may enter blood circulation, lymphatic channel, bone marrow, and even spread to all the tissues and organs.

Correspondence to: Dr Yanbing Wang, Department of Anesthesiology, Bishan Hospital, 9 Shuangxing Road, Bishan, Chongqing 402760, P.R. China

E-mail: wyanbing_bsh@126.com

Key words: lidocaine, skin, malignant melanoma resection
This fact can lead to formation of micro-metastases, increase the risk of postoperative tumor recurrence and metastasis, and also affects postoperative survival rate (6). Thus, the challenge in the treatment strategies, is the combination of chemotherapy, radiation therapy, immunotherapy and targeted therapy, in order to combat the effects of this aggressive disease. There is a necessity of new treatment options (7-10).

In recent years, it has been found that most anesthetics can influence the function of the immune system and target the residual disease or make cells able to form micro-metastasis (11). Regional anesthesia was associated in some studies with reduced risk of cancer recurrence and this can be associated with the anti-inflammatory effects of local anesthetics as lidocaine that can influence the proliferation, migration or invasion of cancer cells (11). Cluster of differentiation 31 (CD31) cells plays an important role in inflammation, oxidative stress generation, cell differentiation, angiogenesis and fibroblasts migration and might be closely related with the skin wound healing process. Sumpio et al determined that CD31 cells play an important role in the formation of tumor blood vessels and its expression can accurately reflect the number of tumor blood vessels (12). Lidocaine directly regulates the molecular and cellular biology of the tumor (11). It is widely believed, that it can not only reduce the gene expression of voltage gated sodium channels (VGSC), but it also inhibits the migration and invasion of tumor cells in vivo. Moreover, it can inhibit tumor growth and proliferation by demethylation of deoxyribonucleic acid (DNA) or by mitogen-activated protein kinase pathway (MAPK) (11). On the other hand, a large number of studies have shown that lidocaine can indirectly affect tumor prognosis by regulating the function of the immune system (11).

This study investigated the effect of lidocaine by CD31 cell modulation on would healing, skin temperature and the infection incidence in vitro and in vivo.

\section{Patients and methods}

Patients. Sixty patients with malignant melanoma treated in the Bishan Hospital from June 2015 to January 2017 were included in the study. The mean age of the patients was $50 \pm 7.2$ years. All the patients included in the study were able to understand and use the visual analogue scale (pain score), they did not have a history of lidocaine allergy and they did not suffer from diabetes or immune system diseases. Also, they 
Table I. Postoperation follow-up results.

\begin{tabular}{lcccc}
\hline Groups & $\begin{array}{c}\text { Metastases } \\
\text { (6 months } \\
\text { after surgery) }\end{array}$ & $\begin{array}{c}\text { Local recurrence } \\
\text { (6 months to } \\
\text { two years after surgery) }\end{array}$ & $\begin{array}{c}\text { Cervical lymph node } \\
\text { metastasis (six months to } \\
\text { two years after surgery) }\end{array}$ & $\begin{array}{c}\text { Death (six months } \\
\text { to two years } \\
\text { after surgery) }\end{array}$ \\
\hline $\begin{array}{l}\text { Lidocaine } \\
\text { Control }\end{array}$ & 1 & 0 & 0 & 0 \\
P-value & 0 & 2 & 2 & 1 \\
\hline
\end{tabular}

presented normal heart, liver and kidney function. The study was approved by the Ethics Committee of Bishan Hospital (Bishan, China), and all the patients signed an informed consent to participate in the study.

Inclusion criteria. The patients included qualified based on the following criteria: The tumor was a first case surface tumor. Primary tumor. Single lesion and tumor with a surface diameter ( $\mathrm{R}) \mathrm{R} \leq 10 \mathrm{~cm}$ and level 1: malignant melanoma in situ, tumor thickness $\leq 1.5 \mathrm{~mm}$ (13). No lymph node or distal metastasis. Complete resection of tumor tissue, i.e., the result of the first examination of frozen specimen report after operation is malignant melanoma.

Preoperative procedures. The diameter of the tumors on the patient's body surface was measured, recorded, and the resection area was marked.

The effect was evaluated by comparing the sign and symptom index before and after treatment: Curative effect index $=[$ (total integral before treatment - total integral after treatment)/total integral before treatment] x100. Grade of healing was evaluated as following: class a healing: good healing and no adverse reactions; class b healing: poor healing with inflammatory reaction at the healing place, such as red swelling, hard knot, hematoma and effusion, but not festering; class c healing: abscess of the incision, which requires incision and drainage.

Surgery. Before the surgery, color doppler ultrasonography and CT examination of superficial lymph nodes were performed to diagnose the metastasis of the tumor and assist in determining the tumor stage. The location and size of the tumor were determined according to the diagnosis. Local anesthesia was used for the operation and the supine position was selected for patients. The range of resection was determined according to the preoperative skin contrast examination and MRI. The melanoma was resected with at least $2 \mathrm{~cm}$ lateral and deep surgical margins when possible or including the deep fascia. Then the tension-free hernioplasty was applicated to repair the wound, to prevent secondary deformity from the wound, and maintain a good form for esthetic principles.

Postoperative wound intervention. The 60 patients included in the study were randomly divided into 2 groups, lidocaine group and control group. The lidocaine group received intradermal injection with 2\% lidocaine solution (approval no. H11020558; Beijing Yongkang Pharmaceutical Co., Ltd., Beijing, China) in dose of $1.5 \mathrm{mg} / \mathrm{kg}$ and the control group received the same
Table II. Infection rate in the two groups.

\begin{tabular}{lcc}
\hline Groups & $\mathrm{n}$ & Infection \\
\hline Lidocaine & 30 & 0 \\
Control & 30 & 1 \\
P-value & & 0.25 \\
\hline
\end{tabular}

quantity of $0.9 \%$ saline solution. The lidocaine was diluted in $0.9 \%$ saline solution. The pain score values, before and after the treatment, were recorded. After the treatment debridement was performed in both groups.

Determination of CD4 T-cell percentage in peripheral blood. From all the patients included in the study venous blood was collected at 3 time-points: T0, before the surgery; T1, $4 \mathrm{~h}$ after the surgery; and T2, $24 \mathrm{~h}$ after the surgery. Lymphocyte CD4 T-cell percentage was determined using BD FACSCount analyzer (BD Biosciences, Franklin Lakes, NJ, USA). Briefly, the reagent tubes were brought to ambient temperature and vortexed upright for $10 \mathrm{sec}$ before using. For analysis, $50 \mu \mathrm{l}$ of whole blood was added to the CD4 reagent tube containing CD3/CD4 PE monoclonal antibodies (BD Biosciences). The tube was incubated in the dark for $30 \mathrm{~min}$ at room temperature and $50 \mu \mathrm{l}$ of fixative (5\% formaldehyde in PBS) was added and vortexed before reading on Becton-Dickinson FACS machine according to manufacturer's instructions using cell count software.

Immunomagnetic separation to collect CD31. The blood collected at $72 \mathrm{~h}$ after surgery from all the patients was used for immunomagnetic separation of CD31 marked immune cells. The sorted cells were added to complete cell culture medium for endothelial cells (including EBM, 2 basal medium enriched with recombinant human epidermal growth factor, insulin-like growth factor, recombinant human fiber cell growth factors, endothelial cell growth factor, fetal bovine serum, ascorbic acid and heparin). The $\mathrm{CD} 31^{+}$cells suspended into DMEM/F-12 medium containing $10 \%$ FBS were inoculated into a 6 -well plate $\left(2 \times 10^{3} / \mathrm{cm}^{2}\right)$ containing collagen of rat tail. The plates were incubated at $37^{\circ} \mathrm{C}$, in $5 \% \mathrm{CO}_{2}$ and $95 \%$ humidity atmosphere. The culture medium was replaced once every 2 days. The cell suspensions were then added to 24 -well culture plate $(0.75 \mathrm{ml}$ in each well, corresponding to $3 \times 10^{5}$ cells). In the lidocaine group we used $1.5 \mathrm{mg} / \mathrm{kg} 2 \%$ lidocaine $(0.75 \mathrm{ml}$ solution included $2 \%$ lidocaine, $0.9 \%$ normal saline and CD31 culture solution). 
Table III. The difference in body temperature between surgical side and healthy side at different times after the surgery in the two groups.

Difference in body temperature between surgical side and healthy side at different times after surgery $\left({ }^{\circ} \mathrm{C}\right)$

\begin{tabular}{lcccccccc}
\cline { 3 - 8 } Groups & No. of patients/group & $4 \mathrm{~h}$ & $6 \mathrm{~h}$ & $8 \mathrm{~h}$ & $10 \mathrm{~h}$ & $12 \mathrm{~h}$ & $24 \mathrm{~h}$ & $48 \mathrm{~h}$ \\
\hline Control & 30 & $2.14 \pm 0.2$ & $3.12 \pm 0.74$ & $3.7 \pm 0.5$ & $3.1 \pm 0.1$ & $2.1 \pm 0.5$ & $2.74 \pm 0.2$ & $2.79 \pm 0.3$ \\
Lidocaine & 30 & $1.8 \pm 0.1$ & $1.3 \pm 0.2$ & $1.1 \pm 0.7$ & $1.0 \pm 0.1$ & $1.1 \pm 0.4$ & $0.8 \pm 0.2$ & $0.6 \pm 0.4$ \\
T-value & & 7.12 & 7.85 & 9.12 & 12.13 & 10.23 & 12.35 & 14.32 \\
P-value & & 0.041 & 0.121 & 0.001 & 0.001 & 0.012 & 0.001 & 0.015 \\
\hline
\end{tabular}

Table IV. VSA pain scores at different times after the surgery in the two groups.

\begin{tabular}{|c|c|c|c|c|c|c|}
\hline \multirow[b]{2}{*}{ Groups } & \multirow[b]{2}{*}{ No. of patients/group } & \multicolumn{5}{|c|}{ VAS pain score at different times after surgery } \\
\hline & & $4 \mathrm{~h}$ & $8 \mathrm{~h}$ & $12 \mathrm{~h}$ & $24 \mathrm{~h}$ & $48 \mathrm{~h}$ \\
\hline Control & 30 & $1.84 \pm 0.52$ & $4.12 \pm 0.74$ & $7.17 \pm 1.5$ & $5.74 \pm 0.2$ & $5.79 \pm 1.3$ \\
\hline Lidocaine & 30 & $0.8 \pm 0.59$ & $1.71 \pm 0.21$ & $2.1 \pm 0.7$ & $2.8 \pm 0.2$ & $2.6 \pm 0.4$ \\
\hline T-value & & 4.12 & 9.85 & 12.12 & 12.45 & 13.32 \\
\hline P-value & & 0.043 & 0.001 & 0.001 & 0.001 & 0.001 \\
\hline
\end{tabular}

In control group, $0.9 \%$ normal saline solution $(0.75 \mathrm{ml}$ solution included $0.9 \%$ normal saline and CD31 culture solution) was used. The cultures were incubated at $37^{\circ} \mathrm{C}$ in $5 \% \mathrm{CO}_{2}$ for $48 \mathrm{~h}$. The 24-well culture plate was centrifuged (1,185 x g for $3 \mathrm{~min})$, the supernatant was discarded, and the CD31 expression was detected by flow cytometry according to the method provided by the supplier.

Measurement of skin temperature. WMY-01 digital thermometer (Shanghai Xing Shuttle Electronic Electric Appliance Co., Ltd., Shanghai, China) was used to measure the body temperature from healthy side and surgical side in each patient at room temperature of $19-22^{\circ} \mathrm{C}$ and $45-65 \%$ humidity.

VAS pain score. Score from 0-10, score 0 point: No pain; score $<3$ points: Slight pain but the patient can tolerate it; score 4-6 points: The patient is in pain and the pain can affect sleep but it still is tolerable; score 7-10 points: The pain of patient is a growing pain and the pain is unbearable.

Statistical analysis. For statistical analysis SPSS software (version 20.0; IBM Corp., Armonk, NY, USA) was used. The data were expressed as mean \pm standard deviation (mean \pm SD). For assessing the differences between the groups, the Mann-Whitney U test was used for numerical data and Chi-square test was used for categorical data. $\mathrm{P}<0.05$ was considered to indicate a statistically significant difference.

\section{Results}

Recurrence of disease. All patients were followed up from 6 months to 2 years. The control group had 2 cases of local
Table V. Wound healing time in the two groups.

\begin{tabular}{lcc}
\hline Groups & $\begin{array}{c}\text { No. of patients/ } \\
\text { group }\end{array}$ & $\begin{array}{c}\text { Wound healing } \\
\text { time (day) }\end{array}$ \\
\hline Lidocaine & 30 & $7.61 \pm 2.30$ \\
Control & 30 & $10.93 \pm 2.29$ \\
Z-value & & 2.92 \\
P-value & & 0.003 \\
\hline
\end{tabular}

recurrence, 2 cases of cervical lymph node metastasis, 1 case of death, and no recurrence or metastasis. On the other hand, the lidocaine group had 1 case of metastasis, 6 months after surgery (Table I).

Skin infection. In patients from lidocaine group no infection was observed compared with the control group, one patient developed infection after the surgery. The infection was caused by the inappropriate protection of the wound and it was not associated with the treatment (Table II).

Skin temperature. The difference in skin temperature between the surgical side and healthy side in lidocaine group was significantly decreased compared with the control group at every time-point. In lidocaine group the difference between body temperature at surgery side and body temperature at healthy side was low and this difference decreased in time. In control group the trend was different, increasing in the first $10 \mathrm{~h}$, then slightly decreased and continued to increase with time (Table III). 
Table VI. Percentages of CD4 T-cells in peripheral blood leucocytes in the groups at different time-points.

Percentages of lymphocytes

\begin{tabular}{lcccc}
\cline { 3 - 4 } Groups & No. of patients/group & T0 & T1 & T2 \\
\hline Control & 30 & $30.859 \pm 9.690 \%$ & $15.665 \pm 8.102 \%$ & $7.482 \pm 3.936 \%$ \\
Lidocaine & 30 & $30.215 \pm 9.871 \%$ & $20.204 \pm 9.886 \%$ & $13.111 \pm 7.365 \%$ \\
Z-value & & 1.12 & 3.14 & 3.21 \\
P-value & & 0.25 & 0.005 & 0.001 \\
\hline
\end{tabular}
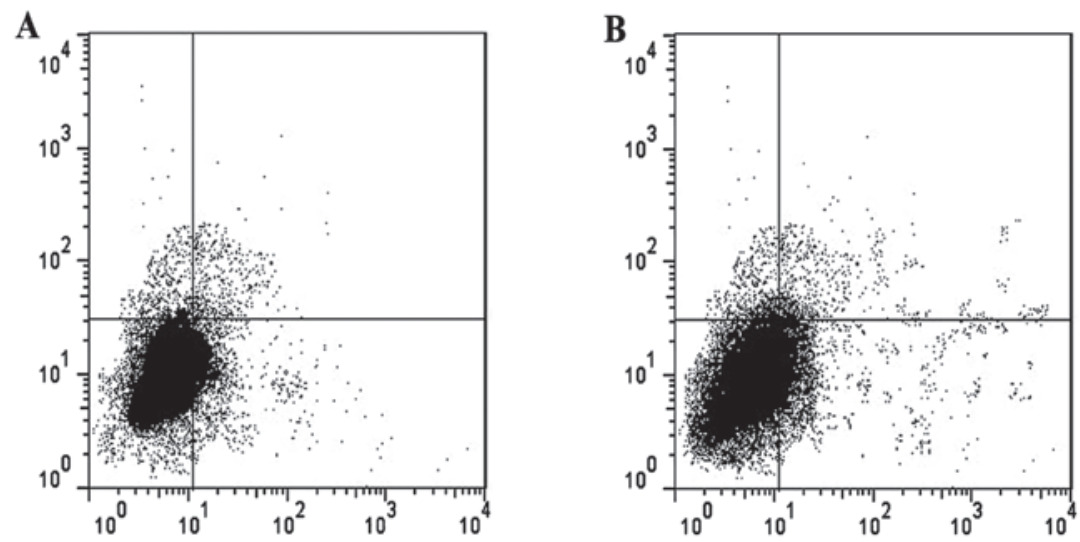

Figure 1. Expression of CD31 in cell cultures. (A) CD31 in lidocaine group; (B) CD31 in control group.

Pain score. The VAS pain score was significantly higher in control group compared with lidocaine group in all time-points. Regarding the VAS score variation between the time-points after the surgery showed an increase at 4,8 and $12 \mathrm{~h}$ after the surgery, followed by a decrease at $24 \mathrm{~h}$ after surgery for the control group and after $48 \mathrm{~h}$ from surgery for lidocaine group (Table IV).

Adverse drug reaction. Regarding the incidence of adverse reactions to the treatment, no drug allergic reaction was observed in either group.

In vitro experiment on cell culture for CD31 cell induction. After induction of CD31 cells in the two groups, their levels were significantly increased in lidocaine group compared to control group. The ratio of CD31 in lidocaine group was $45.54 \pm 0.03 \%$ and the ratio of CD31 in the control group was $28.37 \pm 0.02 \%(\mathrm{P}<0.05)$ (Fig. 1).

Wound healing time. The wound healing time in the experimental group was 4-7 days according to the clinical examination records. The control group healing time averaged from 6 to 10 days. According to the value distribution, the treatment time was not normally distributed, so the rank-sum test was adopted in both groups. The difference between the two groups was statistically significant, and the wound healing time in the experimental group was significantly shorter than that in the control group (Table V).

CD4 T-cell percentage in peripheral blood. At T0 before the surgery there were no differences in the CD4 T-cell percentage in the two groups. We observed that in both groups the percentage of CD4 T-cell decreased after surgery. In comparison with the control group, in lidocaine group the CD4 T-cell percentage was significantly increased at T1 and T2 $(\mathrm{P}<0.05)$ (Table VI).

\section{Discussion}

According to bibliographic data, the incidence of melanoma in China is lower than in Europe, with different clinical features and prognosis (11). Studies have found that in domestic settings the ratio between men's and women's incidence ratio is $0.87: 1$ in China, in Brazil 1:1.4 and in Scotland 1:1.6 in 50 patients with boundary (12). In this study, patients were divided into two groups and it was shown that the difference of average survival time in melanoma patients treated with lidocaine was not significant.

Lidocaine is a type Ib anti-arrhythmic agent and sodium channel antagonist commonly utilized in the cardiac and pain conditions (14). Via its sodium channel blocking the neural conduction is reduced and impeded, leading to its antiarrhythmic and anesthetic properties. Unlike other sodium channel blocking AEDs, such as phenytoin (also a class Ib anti-arrhythmic), its structure includes an aromatic and amine chain motif allowing the binding to the sodium channel via both the channels pore-lining phenyl binding site, or via the external amine chain site, both of which lead to the reduction of ion transport across the cellular membrane. Lidocaine hydrochloride has the advantages of quick action, safety, strong penetration, and possibility of repeatable use. Lidocaine can more rapidly reduce harmful stimulation of peripheral nerve excitability, alleviate nerve dysfunction, achieve the goal 
of relieving itching, improve local blood flow into the body's normal regulating function recovery $(15,16)$.

Pain is the fifth most important inducer of changes in body temperature, pulse, breathing and blood pressure. In this study, except for physical factors, pain may be caused by related psychological stress, such as the fear of disease recurrence, speed of skin recovery, spouse attitude and worries about the children. In order to improve postoperative quality of life, painless treatment is advocated clinically. According to relevant literature, the appropriate method for anesthesia management is direct application to the wound as surface anesthesia (17). Similar to previous studies, this study used lidocaine directly in post-operative skin monitoring and found that it can reduce the pain of debridement. Lidocaine can effectively treat a wide range of wound pain, depending on the scope and drug safety criteria. In clinical practice, medical staff can calculate the dosage based according to the size and area of the wound, and accounting for the safe range of medication. Zhou et al pointed out that CD31 expression level in tumor cells could be used as an indicator to monitor the disease progression and tumor recurrence risk (18). Recently, some researchers tried to add lidocaine to MCF-7 breast cancer cells and then added normal breast epithelium MCF-10, to intervene. They observed the cell vitality by immunofluorescence staining, DNA fragments and WB analysis, and the results showed that lidocaine can inhibit cancer cell activity (19). Interestingly, in the process of cell induction, we found that lidocaine interfered with CD31 cells by stimulating the proliferation and apoptosis. Therefore, we hypothesized that the application of lidocaine on the wound could have some effect on the proliferation of tumor cells.

The lymphocytes have significant influence on the postoperative recovery of patients with melanoma, and a good prognosis is correlated with the content of intratumoral inflammatory infiltrate and the levels of circulatory immune cells $(20,21)$. Previous studies have shown that surgical stress can inhibit lymphocyte proliferation and accelerate apoptosis, leading to lower lymphocyte numbers in the blood circulation $(22,23)$. Studies showed that lidocaine through its anti-inflammatory effects regulation of HPA axis, affect the inflammatory changes that are immune-induced, further affecting lymphocyte proliferation and apoptosis, thus reducing the postoperative immunosuppressive state (11). At T1 and $\mathrm{T} 2$ time-points in both groups of patients the proportions of lymphocytes were lower than at $\mathrm{T} 0$ time-point $(\mathrm{P}<0.05)$. These results are consistent with previous research conclusions, that lidocaine reduce the healing time. Some researchers found that lidocaine through its anti-inflammatory effects on regulation of HPA axis can improve the perioperative activity of lymphocytes, which is confirmed by our study in which we showed an increase of the number of CD $4^{+}$lymphocytes at $\mathrm{T} 2$. However, the molecular mechanism of interaction between lidocaine and the lymphocyte is not yet fully understood, and the relevant separation mechanism needs to be investigated.

Skin temperature, skin tone, tension and capillary recirculation time are the main indications of blood circulation in the body, and skin temperature is the only objective indicator from these indications.

In conclusion, the local application of lidocaine can promote wound healing to a certain extent, reduce pain, and promote postoperative skin reconstruction.

\section{Acknowledgements}

Not applicable.

\section{Funding}

No funding was received.

\section{Availability of data and materials}

The datasets used and/or analyzed during the current study are available from the corresponding author on reasonable request.

\section{Authors' contributions}

KX and YW contributed to the conception and design of the study. JW and LY were responsible for the collection and assembly of data. LW completed data analysis and interpretation. KX and YW contributed to writing the manuscript. All authors read and approved the final manuscript.

\section{Ethics approval and consent to participate}

The study was approved by the Ethics Committee of Bishan Hospital (Bishan, China), and all the patients signed an informed consent to participate in the study.

\section{Patient consent for publication}

Not applicable.

\section{Competing interests}

The authors declare that they have no competing interests.

\section{References}

1. Felcht $\mathrm{M}$ and Thomas M: Angiogenesis in malignant melanoma. J Dtsch Dermatol Ges 13: 125-136, 2015.

2. Zurac S, Neagu M, Constantin C, Cioplea M, Nedelcu R, Bastian A, Popp C, Nichita L, Andrei R, Tebeica T, et al: Variations in the expression of TIMP1, TIMP2 and TIMP3 in cutaneous melanoma with regression and their possible function as prognostic predictors. Oncol Lett 11: 3354-3360, 2016.

3. Ruszkiewicz JA, Pinkas A, Ferrer B, Peres TV, Tsatsakis A and Aschner M: Neurotoxic effect of active ingredients in sunscreen products, a contemporary review. Toxicol Rep 4: 245-259, 2017.

4. Boda D, Docea AO, Calina D, Ilie MA, Caruntu C, Zurac S, Neagu M, Constantin C, Branisteanu DE, Voiculescu V, et al: Human papilloma virus: Apprehending the link with carcinogenesis and unveiling new research avenues (Review). Int J Oncol 52: 637-655, 2018.

5. Danciu C, Oprean C, Coricovac DE, Andreea C, Cimpean A, Radeke H, Soica $\mathrm{C}$ and Dehelean C: Behaviour of four different B16 murine melanoma cell sublines: C57BL/6J skin. Int J Exp Pathol 96: 73-80, 2015.

6. Ma Y, Gui Q and Lang S: Intracranial malignant melanoma: A report of 7 cases. Oncol Lett 10: 2171-2175, 2015.

7. Caunii A, Oprean C, Cristea M, Ivan A, Danciu C, Tatu C, Paunescu V, Marti D, Tzanakakis G, Spandidos DA, et al: Effects of ursolic and oleanolic on SK-MEL-2 melanoma cells: In vitro and in vivo assays. Int J Oncol 51: 1651-1660, 2017.

8. Yang SH, Tsatsakis AM, Tzanakakis G, Kim HS, Le B, Sifaki M, Spandidos DA, Tsukamoto C, Golokhvast KS, Izotov BN, et al: Soyasaponin $\mathrm{Ag}$ inhibits $\alpha-\mathrm{MSH}$-induced melanogenesis in B16F10 melanoma cells via the downregulation of TRP-2. Int J Mol Med 40: 631-636, 2017. 
9. Chalkiadaki G, Nikitovic D, Katonis P, Berdiaki A, Tsatsakis A Kotsikogianni I, Karamanos NK and Tzanakakis GN: Low molecular weight heparin inhibits melanoma cell adhesion and migration through a $\mathrm{PKCa} / \mathrm{JNK}$ signaling pathway inducing actin cytoskeleton changes. Cancer Lett 312: 235-244, 2011.

10. Sevastre B, Sárpataki O, Stan RL, Taulescu M, Sevastre-Berghian AC, Olah NK, Furtuna F, Hanganu D, Hangan AC, Cenariu M, et al: Anticancer activity of Euonymus europaeus fruits extract on human melanoma cells. Farmacia 65: 56-62, 2017.

11. Chamaraux-Tran TN and Piegeler T: The amide local anesthetic lidocaine in cancer surgery - Potential antimetastatic effects and preservation of immune cell function? A Narrative Review. Front Med (Lausanne) 4: 235, 2017.

12. Sumpio BE, Yun S, Cordova AC, Haga M, Zhang J, Koh Y and Madri JA: MAPKs (ERK1/2, p38) and AKT can be phosphorylated by shear stress independently of platelet endothelial cell adhesion molecule-1 (CD31) in vascular endothelial cells. J Biol Chem 280: 11185-11191, 2005.

13. Keohane SG, Proby CM, Newlands C, Motley RJ, Nasr I, Mohd Mustapa MF and Slater DN; British Association of Dermatologists (Squamous and Basal Cell Carcinoma Guideline Development Groups); Royal College of Pathologists (Skin Cancer Lead): The new 8th edition of TNM staging and its implications for skin cancer: a review by the British Association of Dermatologists and the Royal College of Pathologists, U.K. Br J Dermatol 179: 824-828, 2018.

14. Hamano S, Sugiyama N, Yamashita S, Tanaka M, Hayakawa M, Minamitani M, Yoshinari S and Eto Y: Intravenous lidocaine for status epilepticus during childhood. Dev Med Child Neurol 48: 220-222, 2006.

15. Yang YC, Huang CS and Kuo CC: Lidocaine, carbamazepine, and imipramine have partially overlapping binding sites and additive inhibitory effect on neuronal $\mathrm{Na}^{+}$channels. Anesthesiology 113: 160-174, 2010.
16. Aggarwal $P$ and Wali JP: Lidocaine in refractory status epilepticus: A forgotten drug in the emergency department. Am J Emerg Med 11: 243-244, 1993.

17. Lee HJ, Cho YJ, Gong HS, Rhee SH, Park HS and Baek GH: The effect of buffered lidocaine in local anesthesia: A prospective, randomized, double-blind study. J Hand Surg Am 38: 971-975, 2013.

18. Zhou H, Peng G, Song Y, Zhang C and Wang J: Expression of CD31 in the serum of hepatocellular carcinoma patients and the effects of cancer cell migration and proliferation. China J Mod Med 31: 5-9, 2015.

19. Chamaraux-Tran TN, Mathelin C, Aprahamian M, Joshi GP, Tomasetto C, Diemunsch P and Akladios C: Antitumor effects of lidocaine on human breast cancer cells: An in vitro and in vivo experimental trial. Anticancer Res 38: 95-105, 2018.

20. Neagu M, Constantin C and Tanase C: Immune-related biomarkers for diagnosis/prognosis and therapy monitoring of cutaneous melanoma. Expert Rev Mol Diagn 10: 897-919, 2010.

21. Neagu M, Constantin C and Zurac S: Immune parameters in the prognosis and therapy monitoring of cutaneous melanoma patients: Experience, role, and limitations. Biomed Res Int 2013: 107940, 2013.

22. Colucci R and Moretti S: The role of stress and beta-adrenergic system in melanoma: Current knowledge and possible therapeutic options. J Cancer Res Clin Oncol 142: 1021-1029, 2016.

23. Caruntu C, Boda D, Constantin C, Caruntu A and Neagu M: Catecholamines increase in vitro proliferation of murine B16F10 melanoma cells. Acta Endocrinol (Bucur) 10: 545-558, 2014. International (CC BY-NC-ND 4.0) License. 